\title{
Research
}

\section{Assessment partnerships from the start: Building reflective practice as a beginning paramedic student competency}

James Thompson BHIthSc(Hons), BNSG, GradCertHighEduc is Senior Lecturer'; Leah Couzner PhD, BHlthSc(Hons) is Research Assistant'; Don Houston PhD, BA(Hons) is Senior Lecturer $^{2}$

\section{Affiliations:}

'Paramedic Science, Flinders University, Adelaide, South Australia

${ }^{2}$ Centre of Innovation, Learning and Teaching, Flinders University, Adelaide, South Australia

https://doi.org/10.33151/ajp.17.750

\section{Abstract}

\section{Introduction}

The ability to critically self-evaluate is fundamental to professional health roles. Reflective practice is now a recognised feature of the professional capabilities of registered paramedics in Australia, which has implications for both education and industry when determining competency. Reflective practice currently receives little priority in teaching, often appearing late in curriculum and not usually linked to high stakes assessment. It is argued that sustainable reflective practice skills should appear earlier and include opportunities for active student involvement in decisions regarding their learning. Student-tutor consensus assessment (STCA) is a reflection-in-practice technique providing a structured approach for critically appraising practice, while calibrating judgement with assessors. We evaluated the experiences of a cohort of newly commencing undergraduates within a fundamentals of paramedic practice subject.

\section{Methods}

Students were invited to complete a questionnaire relating to their perceptions and experiences after participating in the STCA approach.

\section{Results}

88 responses were collected which indicated broad agreement regarding the value to learning and recognition for the importance of reflective practice skills to future professional roles.

\section{Conclusion}

Students readily embraced the principles of reflective practice and were able to effectively contribute to high level decisions regarding their work despite having only recently commenced the program. In addition, the high levels of broad agreement for the value of the STCA approach, suggest reflective practice and critical thinking-based assessments have a more important role to play in paramedic education.

\section{Keywords:}

reflective practice; students as partners; paramedic competency; paramedic education

Corresponding Author: James Thompson, james.thompson@flinders.edu.au 


\section{Introduction}

The recent launch of national registration for paramedics in Australia coincided with the publication of a set of professional capabilities, setting out the minimum expectations of knowledge and skills for practice under the paramedic title. The Australian Health Practitioner Regulation Agency (AHPRA) document identifies critical thinking and reflective practice as key components of the evidence-based practice requirements for registered paramedics (1). These skills are fundamental to a role which is characterised by unpredictable clinical variables. However, they are often underrepresented when assessing competency $(2,3)$, or restricted to the later stages of university programs. Similar to other health disciplines, Australian university paramedic courses traditionally start with foundation knowledge for practice, before layering disease conditions, then clinical management principles. From our experience as paramedic educators, once foundational knowledge is established clinical reasoning and reflective practice skills start to become more prominent in teaching. However, in paramedic education, students embark on placements from the outset of their studies, immediately exposing them to a complex casemix of patients and a myriad of conditions. Consequently, their learning does not always follow the curriculum map, but is more reactive to varied and unpredictable learning encounters. It is also perplexing that when assessing the effectiveness of critical thinking and reflective practice skills, high stakes decisions are restricted to the tutor, excluding the student judgement. Van Der Vleuten and Schuwith note the contradiction of requiring the learners to self-regulate their learning, while also being required to successfully pass teacher-led assessments or tests (4). An argument exists to embed reflective practice much earlier and to include students in decision-making about the quality of their own work (5-7) if they are to develop the sustainable skills needed to critically appraise their future practice.

Reflective practice is a mechanism which supports the growth of knowledge and skills through critical evaluation of events (810). Limiting student exposure to these essential skills is a lost learning opportunity. Student assessment and determinations of competence remain contentious topics $(11,12)$.

\section{Reflection and reflective practice}

Reflection skills now feature as mandated competency requirements of most recognised professions (13-15). However, the liberal use of a range of terms interchangeably shows that understanding and application of reflection within disciplines is not homogenous (16). The terms 'reflection' and 'reflective practice' are examples of code which can hold unique meaning in different contexts. Differentiating these terms, reflection can be simply viewed as the act of looking back (14). Building on reflection as a single act, Schon's seminal work on 'the reflective practitioner' identifies reflective practice as a tool by which to apply reflection (17). This enables reflection to be considered in terms of reflection-on-action and reflectionin-action, separating outcome and process (18). Expanding on these concepts further are the numerous research contributions towards the principles of evaluative judgement and self-regulated learning. Evaluative judgement concerns the evaluation of one's own or others' work (19). Self-regulated learning looks to the development of the self which comes from using these processes (20). In the context for contemporary paramedic practice, AHPRA Professional Capabilities for Registered Paramedics now emphasise the requirements for logical problem solving, critical and reflective thinking about the effectiveness of a paramedic's actions (21). As university education is tasked with contributing to the development of paramedics who require these skills for practice, it is appropriate for students to receive training and opportunity to exercise reflection-in-action and reflection-on-action to help build their capacity for effective evaluative judgement about their own performance.

\section{Challenges with assessing paramedic competence}

The early phases of paramedic education emphasise the foundation skills required for safe and competent entry level practice. A discipline with military origins, the legacy of regimented approaches towards determining competent practice are still evident, such as the guidelines and protocols which govern the actions of employees. The influence of these standing orders extends to teaching and assessment within the classroom, with students instructed that when they encounter a patient who satisfies criteria ' $x$ ', then treatment ' $y$ ' is indicated. Predicted responses and key points are collated into rubrics, which underpin the credentialing of student competency (with tutors able to check off whether the rules for practice have been met). Usually starting with a small number of steps associated with simple psychometric tasks, rubrics become increasingly complex as teachers try to accommodate additional elements. The limitations of competency focussed rubrics are exposed when they fail to predict significant variables, when multiple acceptable responses exist, or when a binary check-box approach tries to faithfully capture qualitative data $(22,23)$. Assigning competency from singlefaceted assessments remains contentious, as simply delivering automated reactions when triggered by a clinical indicator fails to represent the complete picture of competence (24). Nontechnical attributes, such as communication and reflection, are essential requirements for a practitioner whose primary focus is human agency $(25,26)$ and deeming a student competent infers they have demonstrated adequate knowledge, skills and judgement $(27,28)$, which cannot be demonstrated through simple task-based exercises. Competency demands assessment be multifaceted and acknowledge the importance of the domain and integration of the task (22). Domain - the authenticity of the context for assessment - is cited as one of the most significant contributors to the reliability of assessing for student competence (12). The importance of the environmental context has implications for tutors attempting to assess student competence. Additionally, the problem solving approaches demonstrated by students can often be more telling than the actual outcomes they arrive at (29). While the absence of a critical error may satisfy a rubric, it is how a student works 
through problems and applies knowledge and skills that offers much greater insight to their true abilities. This data is seldom captured in competency-based assessment. Typically, the assessment of paramedic practice within university settings involves the student performing tasks, and the observing assessor awarding their summative evaluation. All judgement decisions reside with the tutor, with the student passive. This can contribute to power tensions between students and those judging them, or lead to students regarding the process of assessment as punitive (30), a perception which is perpetuated when the focus of assessment is primarily finding student deficiencies (31). This has fuelled growing criticism for models which do not allow for student input or restricts the options for students to challenge tutor decisions (32).

Summative assessment has long been the mainstay of paramedic education, where credentialing practices provide assurance that the standards and expectations of stakeholders have been met (33). Assessment is a widely recognised driver for learning $(34,35)$ and the desire to perform well in summative tests can be a powerful motivator for students. When it comes to learning impact however, feedback has been identified as the single most influential factor (36). Feedback is not normally a prominent feature in summative assessment. Simply issuing test results is no substitute for high quality feedback (37) with check box approaches regarded as the poorest form of feedback (36). Conventional competency rubrics relay a tutor's judgements usually in the form of a score, but highquality feedback requires a discourse between student and assessor (38). Feedback enables students to be guided in further development of knowledge, skills or attitude (39). It is reasonable to expect assessment which is used to determine paramedic competency to consider the unique domain of the discipline, be multifaceted and be learner centric.

\section{Taking teaching inspiration from on-road practice}

AHPRA Professional Capabilities for Registered Paramedics explicitly include reflective practice as a competency for paramedic practice (21). Paramedics in the field often exercise reflective practice. Based on student reports and observed practices of paramedics, crews commonly unpack the events following the completion of a case, critiquing effectiveness of their management, identifying opportunities to improve practice and highlighting knowledge gaps. In the case of junior and developing paramedics this ritual is a learning event, with the novice encouraged to present their understanding before receiving their senior colleagues' appraisal. Joining the discussion only once the developing paramedic has declared their own case reflection, senior input is able to provide clarification, endorsement or advice. This active two-way exchange is characterised by comprehensive explanations and often underpinned with teaching concepts. Discussion around challenges as well as successes is equally encouraged in a process designed to calibrate staff judgement. It is through analysing events and auditing the efficacy of their practices, that clinicians can gain valuable experiential learning and self-improve $(40,41)$. Despite varying definitions of reflective practice, the literature identifies these consistent features of revisiting experiences in order to progress learning into the future (42).

\section{The student-tutor consensus assessment design}

The STCA design, which echoes the on-road discourse, was developed after efforts to incorporate other reflective practice approaches into learning experiences proved unsuccessful. Our response was to develop a reflective practice assessment shaped by the on-road practices of paramedics. We considered incorporating paramedic reflective practice principles into the classroom would enhance the validity of our assessments, increasing the breadth of features required to be considered for determining competency. The STCA was first developed and trialled with a final year cohort undertaking a paramedic capstone subject in $2015(30,43)$. For some time, this subject had been plagued by competitive student behaviours which prioritised grade-seeking ahead of learning acquisition. These competitive behaviours derailed collaborative learning designs, and it was common for students to attempt to conceal mistakes, an action with potentially catastrophic consequences if carried into the real-world. Any educational goals relating to quality patient care or optimal health outcomes, were sidelined by students prioritising their individual results (44). It became evident that these frustrating behaviours were symptoms of the teaching and assessment systems which enabled and rewarded them.

The STCA imitates the reflective practices seen in industry. First, students attempt a simulated pre-hospital scenario observed by tutors, who record a score in line with the proficiency of practice and likely effectiveness of case outcomes. However, this judgement is withheld initially, with students being first encouraged to critique each of the components of the case in line with the steps of the paramedic process of care (45). Optimal patient care is used as the benchmark for all decisions of effectiveness. Detailed discussion is encouraged before students are required to determine whether each individual criterion was satisfied. Only when the student has finished sharing their critique is the tutor judgement shared with the student. Starting with their own rating of the scenario, the tutor declares their original score and expands on their rationale. This step is interactive with students encouraged to question tutors. The tutor simply follows the student's earlier self-critique criteria, with their own appraisal of each criterion, validating or disagreeing with the student judgement by way of a comprehensive explanation and two-way discourse with students. Marks are awarded each time the student and tutor appraisals are in consensus. With scores reflecting consensus, student mistakes or omissions are rewarded instead of being penalised when they are identified by both student and assessor, motivating students to declare their mistakes and suggest improvements. The final score for the assessment represents the overall case performance (the tutor's score based on their observations) and a tally of the 
consensus score (student reflective judgement calibrated to that of their assessor). A summary of the STCA approach is illustrated in Figure 1.

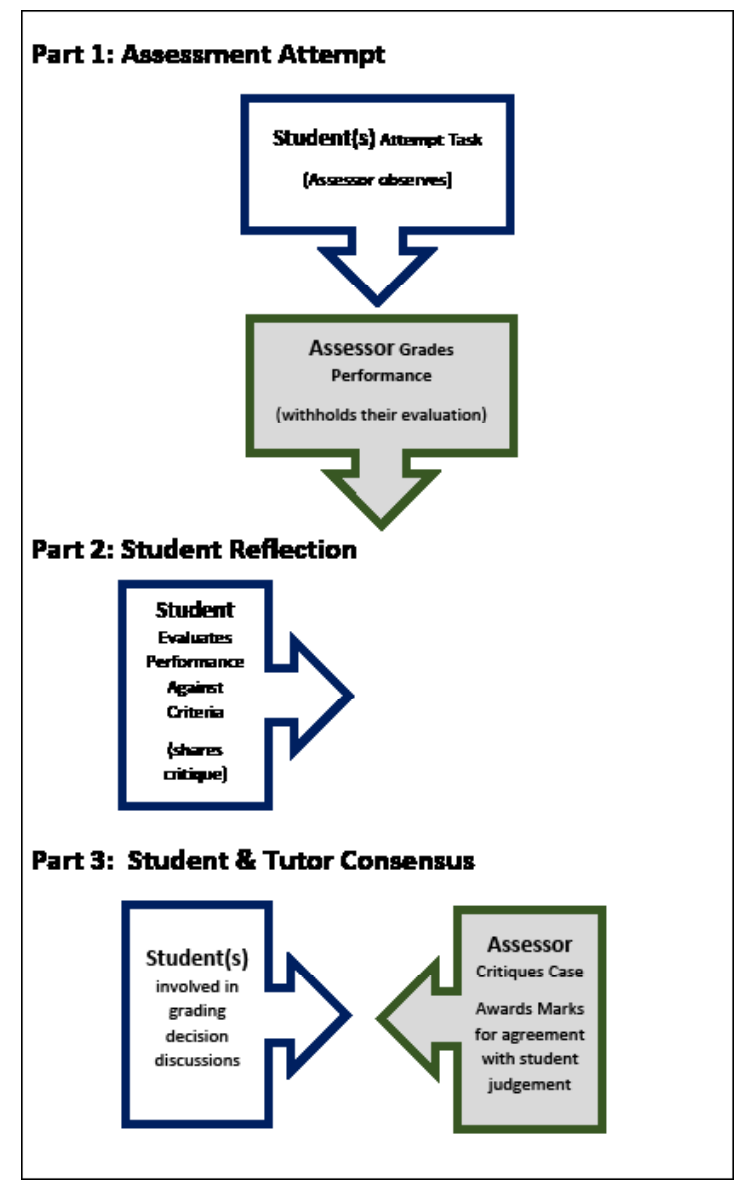

Figure 1. Student-tutor consensus assessment process

\section{Implementation and evaluation of the STCA with first year paramedic students}

The original STCA was introduced and studied with a cohort of third year paramedic students that explored the use of assessment for learning practices as a means for enhancing the work-ready capabilities of paramedic graduates $(30,43)$. The evaluation of the initiative demonstrated that the approach was extremely well received by students and had a positive effect on their learning (30). This success prompted the decision to trial it with first year students in an attempt to promote the development of critical thinking and self-reflection skills from the outset of the degree. The STCA was therefore introduced as an assessment method within a first year paramedic practice subject. This represented a major change to the assessment expectations for the beginning student who is yet to establish knowledge and skills foundations. Therefore, we were especially interested to explore student responses to the innovation. The research question for this project was: What are the perceptions of first year students of the effectiveness and value of the STCA in relation to their learning? This paper reports on the perceptions of the firstyear student cohort following their completion of the STCA and presents key considerations for paramedic student learning, assessment and competencies.

\section{Methods}

This component of the research involved student self-rated perceptions and experiences with the STCA. Approval was provided by the Flinders University Social and Behavioural Research Ethics Committee. Students were informed of the project in advance via the topic's online learning platform. Participants were advised all responses would be de-identified, that their participation was anonymous and voluntary, and that their participation was in no way linked to their academic progress. A paper-based questionnaire was administered in class by a non-academic staff member following the completion of all teaching requirements of the subject, which took approximately 15 minutes to complete. The format mirrored standard student feedback questionnaires that routinely accompany university subjects: a document familiar to the student participants. The questions contained in the survey deliberately explored a range of statements which represent a range of concepts embodying reflective practice within the context of the paramedic discipline.

We presented the same questionnaire to the first year students that was administered to the final year student cohort several years earlier when the STCA was first evaluated. It featured a series of eight statements, to which students were asked to rate their level of agreement on a Likert scale ranging from 1 (strongly disagree) through to 5 (strongly agree).

\section{Analysis}

Descriptive statistics were used to explore the education and employment background of the students before enrolling in the Bachelor of Paramedic Science degree, and also their responses to the eight questionnaire items relating to the STCA.

In order to measure the students' overall agreement with the concept of the STCA, principal axis factoring was performed. The results indicated that the students' responses to the eight questionnaire items could be combined into a single value for each student representing their overall agreement with the concept of the STCA (one factor with an eigenvalue exceeding 1.0 (4.86), explaining $60.74 \%$ of the variance). This 'overall agreement' value was calculated for each student by calculating the mean of their responses to each of the eight questionnaire items, with the resulting value ranging from 1 (indicating strong disagreement with STCA) to 5 (indicating strong agreement with STCA). Before this, Bartlett's Test of Sphericity ( $p \leq .000)$ and the Kaiser-Myer-Olkin Measure of Sampling Adequacy $(\mathrm{KMO}=0.89)$ were conducted to establish that the data was appropriate for principal axis factoring.

To determine whether students' educational and employment background had an influence on their views regarding the STCA, a one-way ANOVA was performed. All analyses were undertaken using version of 25 of IMB SPSS Statistics. 


\section{Results}

88 ( $88 \%$ of possible responses from the cohort) anonymous questionnaires were completed and returned. The majority of students ( $n=48,55 \%$ ) identified themselves as 'school leavers', having commenced their degree immediately following the completion of their secondary schooling. This was followed by students who had transferred from another degree $(n=21$, $24 \%)$ and $18 \%(n=16)$ who identified themselves as being a 'mature aged student'. The remaining students comprised of one international student and two who selected the response option of 'other' but provided no further information. Only one participant, a mature aged student, identified themselves as having prior ambulance industry experience. The responses to the STCA related questionnaire components are presented in Table 1.

Overall, the students demonstrated a positive attitude towards the experience of the STCA. On a scale from 1 (indicating strong disagreement) to 5 (indicating strong agreement), the students had a mean level of agreement of 4.36. The students demonstrated agreement with all of the individual statements that they were asked to consider, although they agreed with some statements more strongly than others. The statement that students demonstrated the highest level of agreement with related to self-assessment being an important skill for paramedics, with $98 \%$ ( $n=86$ ) of students either agreeing or strongly agreeing with this statement. The statement that students demonstrated the lowest level of agreement with related to their preparedness for a paramedic role, however high levels of agreement were still evident, with $73 \%(n=64)$ of students either agreeing or strongly agreeing. This statement having the lowest level of agreement was to be expected given that the students were in their first year of the degree with limited clinical experience. The students' education and employment background before entering the degree was found to have no statistically significant impact on their agreement with the overall concept of the $\operatorname{STCA}(F(2,85)=0.78, p=.46)$. While school leavers demonstrated lower levels of agreement than mature aged students (mean difference $-.07,95 \% \mathrm{Cl}-.36$ to .24) and 'other' students (tertiary transfer, international and students who did not provide details to the question) (mean difference $-.17,95 \% \mathrm{Cl}-.43$ to .07 ), it was not to a level of statistical significance.

Table1. Beginning student response ratings to student-tutor consensus assessment

\begin{tabular}{|l|c|c|c|c|c|c|c|c|}
\hline & $\begin{array}{c}\text { Strongly } \\
\text { disagree } \\
\mathrm{N}\end{array}$ & $\begin{array}{c}\text { Disagree } \\
\mathrm{N}\end{array}$ & $\begin{array}{c}\text { Neither } \\
\text { agree } \\
\text { disagree } \\
\mathrm{N}\end{array}$ & $\begin{array}{c}\text { Agree } \\
\mathrm{N}\end{array}$ & $\begin{array}{c}\text { Strongly } \\
\text { agree } \\
\mathrm{N}\end{array}$ & $\begin{array}{c}\text { Not } \\
\text { answered } \\
\mathrm{N}\end{array}$ & $\begin{array}{c}\text { Total } \\
\mathrm{N}\end{array}$ & $\begin{array}{c}\text { Mean* } \\
\mathrm{N}\end{array}$ \\
\hline $\begin{array}{l}\text { Self-assessment is } \\
\text { an important skill for } \\
\text { paramedics }\end{array}$ & $1(1 \%)$ & $0(0 \%)$ & $1(1 \%)$ & $28(32 \%)$ & $58(66 \%)$ & $0(0 \%)$ & $88(100 \%)$ & 4.61 \\
\hline $\begin{array}{l}\text { I learned through observing } \\
\text { my peers being assessed }\end{array}$ & $1(1 \%)$ & $1(1 \%)$ & $0(0 \%)$ & $39(44 \%)$ & $47(53 \%)$ & $0(0 \%)$ & $88(100 \%)$ & 4.48 \\
\hline $\begin{array}{l}\text { I found the student-tutor } \\
\text { consensus marking format } \\
\text { helped me to develop } \\
\text { skills I can use in my future } \\
\text { profession }\end{array}$ & $1(1 \%)$ & $2(2 \%)$ & $1(1 \%)$ & $34(39 \%)$ & $49(56 \%)$ & $1(1 \%)$ & $88(100 \%)$ & 4.47 \\
\hline $\begin{array}{l}\text { I found the student-tutor } \\
\text { consensus marking format } \\
\text { effective for my learning }\end{array}$ & $1(1 \%)$ & $2(2 \%)$ & $1(1 \%)$ & $35(40 \%)$ & $49(56 \%)$ & $0(0 \%)$ & $88(100 \%)$ & 4.47 \\
\hline $\begin{array}{l}\text { The scenarios effectively } \\
\text { combined my knowledge, } \\
\text { reasoning and practical } \\
\text { skills }\end{array}$ & $1(1 \%)$ & $0(0 \%)$ & $0(0 \%)$ & $44(50 \%)$ & $43(49 \%)$ & $0(0 \%)$ & $88(100 \%)$ & 4.45 \\
\hline $\begin{array}{l}\text { Overall I am more confident } \\
\text { in my knowledge and } \\
\text { practice }\end{array}$ & $1(1 \%)$ & $0(0 \%)$ & $4(5 \%)$ & $46(52 \%)$ & $37(42 \%)$ & $0(0 \%)$ & $88(100 \%)$ & 4.34 \\
\hline $\begin{array}{l}\text { I found the student-tutor } \\
\text { consensus marking format } \\
\text { fair }\end{array}$ & $2(2 \%)$ & $2(2 \%)$ & $7(8 \%)$ & $45(51 \%)$ & $32(36 \%)$ & $0(0 \%)$ & $88(100 \%)$ & 4.17 \\
\hline $\begin{array}{l}\text { I feel I am well prepared for } \\
\text { a paramedic role }\end{array}$ & $1(1 \%)$ & $2(2 \%)$ & $21(24 \%)$ & $44(50 \%)$ & $20(23 \%)$ & $0(0 \%)$ & $88(100 \%)$ & 3.91 \\
\hline
\end{tabular}




\section{Discussion}

Unlike participants in the original study, this cohort had limited prior experience with competency-based education. When introduced to the STCA, these students were yet to establish the same knowledge foundations as final year students, however this did not appear to affect their appreciation for reflective practice skills or willingness to embrace the approach. Student responses suggested that through the STCA they were able to reflect on their practice performance considering the multiple facets of knowledge, reasoning and skills simultaneously. In determining the competency of a clinician, it is essential not just to consider the components as individual elements, but also the way these parts interact (31). Clinical competence denotes more than a capacity to respond to a known event with a pre-practised action; it includes holistic skills, attitudes, knowledge and values (46). Reflective practice is an integral competency of the current professional capabilities for paramedics (21). The students' recognition of an interaction between their knowledge, skills and reasoning, and reflection on their practice, provides a significant advancement on the summative methods traditionally used. This observation was consistent with the views of the paramedic tutors recruited from local industry, who conveyed a preference for the STCA rather than being constrained to traditional rigid grading rubrics during sessional debriefs following each class. Bi-partisan discussions and recognition for the value of subjective assessor input were also reported to be a more authentic approach to critiquing paramedic practice. The questionnaire statements pertaining to student confidence and preparedness were originally designed with the final year student in mind, and particularly their transition from higher education to the workforce. Although these may seem poorly placed questions for the beginning student, they do relate to the broader concept of certifying competence. Extending on Millers' original pyramid design for determining the knowledge and performance achievement levels for students, Cruess et al identified the pinnacle of student attainment as achieving the level of professional identity labelled as 'IS' (47). At this level, a student had moved beyond the distinctive levels of knowing, and knowing and showing how, and had transcended into a state where they were thinking, acting and behaving as a member of the profession. Considering this as an optimal goal of paramedic education, perceptions of confidence and preparedness for the role seem relevant themes for educators to track across the span of a degree.

Empowering student decision-making is additionally important. By sharing a critical review of their work, students can demonstrate what they have learned 'from' the test, instead of simply how well they have done. Students are often aware when they have made mistakes, particularly when simulated patient scenarios deteriorate based on their decisions or treatment. The STCA promotes the acknowledgement of judgement errors, celebrating their contributions towards learning. For programs seeking to develop critical thinking capacity, building student skills in critically appraising their work represents sustainable learning. Re-configuring the role of students within assessment, the STCA exemplifies the theme of 'students as partners' which is gaining increasing attention within higher education (48). Where focus for student roles in teaching and assessment is usually directed towards the co-production of learning design $(48,49)$, the STCA sees this partnership extended to grade decisions.

A common academic complaint shared by industry partners has historically concerned student reluctance or difficulties in receiving critical feedback. Although the variables that may influence this are complex and likely unique to each case, a paramedic grading system which is based principally on penalising faults is certainly a contributing factor. The STCA approach uses assessment as a vehicle to initiate a professional and bi-partisan conversation about competencybased assessment events. When considering the advances to assessment that the STCA achieves, the alternative simple task and student sign off approach seems redundant.

Although this research was part of larger project it is a smallscale investigation with a single cohort of first year students, therefore care is required in generalising results to wider contexts.

\section{Conclusion}

Clinical competency is an essential requirement of the paramedic and a goal which universities strive to have their students attain. Standard skills sign-off grading approaches respond to only a portion of the necessary elements required to effectively credential competency. The STCA empowers students to play active roles within decision making regarding their own work and reprioritises the accountability to patient care ahead of their individual performance scores. It is flexible enough to capture the full breadth of professional considerations required to certify competence. Importantly for educators, the approach chronicles not only how a student performs in a test, but equally a demonstration of the learning they obtain resulting from the assessment event. The introduction of this novel assessment approach to first year students marked a significant re-think of the needs and capabilities of the beginning students. Favourable participant responses and feedback reflected how readily students embraced an approach which is now extensively used throughout all levels of our paramedic teaching. Developing student reflective practice skills previously has been postponed until a foundation of knowledge or skills have first been laid. This project has demonstrated that beginning students are willing to embrace the opportunity to make reflective practice judgements about their work and recognise the importance of being able to do so. 


\section{Competing interests}

The authors have no competing interests. Each author of this paper has completed the ICMJE conflict of interest statement.

\section{References}

1. AHPRA. Professional capabilities for registered paramedics. Paramedicine Board of Australia 2018. Available at: www. paramedicineboard.gov.au/Professional-standards/ Professional-capabilities-for-registered-paramedics.aspx

2. Epstein RM, Hundert EM. Defining and assessing professional competence. JAMA 2002;287:226-35.

3. Schuwirth LW, Van Der Vleuten CP. Current assessment in medical education: programmatic assessment. Journal of Applied Testing Technology 2019;20(S2):2-10.

4. van Der Vleuten CP, Schuwirth LW. Assessment in the context of problem-based learning. Adv Health Sci Educ Theory Pract 2019;24:903-14.

5. Cowan J. Developing the ability for making evaluative judgements. Teaching in Higher Education 2010;15:323-34.

6. Boud D, Falchikov N, editors. Rethinking assessment in higher education: learning for the longer term. London, England: Taylor \& Francis, 2007, p. 181-97.

7. Tai J, Ajjawi R, Boud D, Dawson P, Panadero E. Developing evaluative judgement: enabling students to make decisions about the quality of work. High Educ 2018;76:467-81.

8. Brookfield S. Critically reflective practice. J Contin Educ Health Prof 1998;18:197-205.

9. Thompson N, Pascal J. Developing critically reflective practice. Reflective Practice 2012;13:311-25.

10. Russell T. Can reflective practice be taught? ibid. 2005;6:199-204.

11. Clinton M, Murrells T, Robinson S. Assessing competency in nursing: a comparison of nurses prepared through degree and diploma programmes. J Clin Nurs 2005;14:82-94.

12.Van Der Vleuten CP, Schuwirth LW. Assessing professional competence: from methods to programmes. Med Educ 2005;39:309-17.

13. Argyris C, Schon DA. Theory in practice: increasing professional effectiveness. San Francisco: Jossey-Bass; 1974.

14.Mann K, Gordon J, MacLeod A. Reflection and reflective practice in health professions education: a systematic review. Adv Health Sci Educ Theory Pract 2009;14:595-621.

15.Boud D, Keogh R, Walker D. Reflection: Turning experience into learning: Routledge; 2013.

16. Vince R, Reynolds M. Reflection, reflective practice and organizing reflection. The SAGE Handbook of Management Learning, Education and Development. Sage Publications, 2009.

17.Schön DA. Educating the reflective practitioner. JosseyBass, 1987.

18. Yanow D, Tsoukas H. What is reflectionlinlaction? A phenomenological account. Journal of Management Studies
2009;46:1339-64.

19.Panadero E, Broadbent J. Developing evaluative judgement: a self-regulated learning perspective. In: Boud D, Ajjawi R, Dawson P, Tai J, editors. Abingdon: Routledge, 2018.

20.Pintrich PR, De Groot EV. Motivational and self-regulated learning components of classroom academic performance. Journal of Educational Psychology 1990;82:33.

21.AHPRA. Professional capabilities for registered paramedics. Paramedicine Board of Australia 2019. Available at: www. paramedicineboard.gov.au/Professional-standards/ Professional-capabilities-for-registered-paramedics.aspx

22. Tavares W, Boet S, Theriault R, Mallette T, Eva KW. Global rating scale for the assessment of paramedic clinical competence. Prehosp Emerg Care 2013;17:57-67.

23.Meier RL, Williams MR, Humphreys MA. Refocusing our efforts: assessing nonitechnical competency gaps. Journal of Engineering Education 2000;89:377-85.

24.Nicol DJ, MacfarlaneIDick D. Formative assessment and selfrregulated learning: a model and seven principles of good feedback practice. Studies in Higher Education 2006;31:199-218.

25. Reronr R. Comparing the psychometric properties of checklists and global rating scales for assessing performance on an GSCE-format examination. Acad Med 1998;73:993-7.

26.Wikinson TJ, Frampton CM, Thompson-Fawcett M, Egan T. Objectivity in objective structured clinical examinations: checklists are no substitute for examiner commitment. Acad Med 2003;78:219-23.

27.Miller GE. The assessment of clinical skills/competence/ performance. ibid. 1990;65:S63-7.

28.Govaerts MJ, Van der Vleuten CP, Schuwirth LW, Muijtjens AM. Broadening perspectives on clinical performance assessment: rethinking the nature of in-training assessment. Adv Health Sci Educ Theory Pract 2007;12:239-60.

29. Schuwirth L, Southgate L, Page G, et al. When enough is enough: a conceptual basis for fair and defensible practice performance assessment. Med Educ 2002;36:925-30.

30. Thompson J, Houston D, Dansie K, et al. Student \& tutor consensus: a partnership in assessment for learning. Assess Eval High Educ 2016;1-11.

31.Schuwirth L, Ash J. Assessing tomorrow's learners: in competency-based education only a radically different holistic method of assessment will work. Six things we could forget. Med Teach 2013;35:555-9.

32.Bond $\mathrm{H}$, Spurritt D. Challenges of assessment. Educating beginning practitioners: challenges for health professional education. Butterworth-Heinemann, Oxford, 1999, p. 22835.

33.Brookhart SM. Successful students' formative and summative uses of assessment information. Assess Educ 2001;8:153-69.

34.Brown S. Assessment for learning. Learning and Teaching in Higher Education 2005;81-9.

35.Wiliam D. What is assessment for learning? Studies in Educational Evaluation 2011;37:3-14. 


\section{References (continued)}

36. Hattie J, Timperley H. The power of feedback. Rev Educ Res 2007;77:81-112.

37. Biggs J. Assessment and classroom learning: a role for summative assessment? Assess Educ 1998;5:103-10.

38. Hodges B, McNaughton N, Tiberius R. OSCE checklists do not capture increasing levels of expertise. Acad Med 1999;74:1129-34.

39. Holmboe ES, Sherbino J, Long DM, Swing SR, Frank JR, Collaborators IC. The role of assessment in competencybased medical education. Med Teach 2010;32:676-82.

40.Paterson C, Chapman J. Enhancing skills of critical reflection to evidence learning in professional practice. Phys Ther Sport 2013;14:133-8.

41. Mann K, Gordon J, MacLeod A. Reflection and reflective practice in health professions education: a systematic review. Adv Health Sci Educ Theory Pract 2009;14:595-621.

42. Husebø SE, O'Regan S, Nestel D. Reflective practice and its role in simulation. Clin Simul Nurs 2015;11:368-75.
43. Thompson J, Houston D, Dansie K. Teaching students to think like a paramedic: improving professional judgement through assessment conversations. Australasian Journal of Paramedicine 2017;14(4).

44. Thompson J, Grantham H, Houston D. Paramedic capstone education model: building work ready graduates. ibid. 2015;12(3).

45.Carter H, Thompson J. Defining the paramedic process. Aust J Prim Health 2015;21:22-6.

46. Yanhua C, Watson R. A review of clinical competence assessment in nursing. Nurse Educ Today 2011;31:832-6.

47.Cruess RL, Cruess SR, Steinert Y. Amending Miller's pyramid to include professional identity formation. Acad Med 2016;91:180-5.

48. Matthews K. Students as partners as the future of student engagement. Student Engagement in Higher Education Journal 2016;1(1).

49. Healey M, editor. Students as partners in learning and teaching in higher education. Workshop Presented at University College Cork; 2014. 